\title{
Minimally Invasive Coronary Surgery
}

\author{
Mirko Todić,, 2 Vanja Drljević-Todić, ${ }^{3}$ Andrej Preveden, ${ }^{1,2}$ Aleksandar Redžek, ${ }^{1,2}$ \\ Mihaela Preveden, ${ }^{1}$ Ranko Zdravković, ${ }^{1}$ Novica Kalinić ${ }^{4}$
}

\begin{abstract}
Minimally invasive options for coronary artery bypass graft (CABG) surgery progressed dramatically in the last decades. Minimally invasive CABG surgery is presented trough these forms: minimally invasive direct coronary artery bypass (MIDCAB), endoscopic atraumatic coronary artery bypass (EndoACAB), robot-assisted direct coronary artery bypass (RADCAB), total endoscopic coronary artery bypass (TECAB), and hybrid coronary revascularisation (HCR). Unfortunately, these are still limited only to the specialised centres across the world and have not been accepted by the majority of cardiac surgeons. A surgeon who is starting to practice minimally invasive CABG surgery needs to be ready for long duration of the interventions, higher rate of conversions to sternotomy and significant learning curve. Excellent results that have been published on the subject of minimally invasive revascularisation methods support the potential of these alternative approaches to evolve in the near future.
\end{abstract}

Key words: Minimally invasive heart surgery; Coronary surgery; Midcab; Endoacab; Radcab; Tecab; Hybrid revascularisation.
(1) Institute of Cardiovascular Diseases of Vojvodina, Clinic for Cardiovascular Surgery, Sremska Kamenica, Serbia.

(2) Faculty of Medicine, University of Novi Sad, Novi Sad, Serbia. Institute of Cardiovascular Diseases of (3) Vojvodina, Clinic for Cardiology, Sremska Kamenica, Serbia.

(4) University Clinical Centre of the Republic of Srpska, Banja Luka, the Republic of Srpska.

Correspondence: MIRKO TODIĆ

E: todicmirko@yahoo.com

\section{ARTICLE INFO}

Submitted: 4 October 2021 Accepted: 2 November 2021

\section{Introduction}

Cardiac surgeons invested a great amount of effort in development of minimally invasive methods for the last couple of decades. The advance in modern technologies supported those efforts, and therefore enabled performing coronary artery bypass graft (CABG), valvular, great vessels and other cardiac surgery procedures, without total median sternotomy (TMS) - traditional, utterly invasive approach. The cooperation between cardiac surgeons and interventional cardiologists led to novel minimally invasive methods which benefit with the best from both worlds - surgical technique and precision and catheterisation-based approach.

Minimally invasive options for CABG surgery (miniCABG) progressed dramatically in the last decade. The topic of this paper will be all of those who do not require TMS. Although partial sternotomy (ministernotomy) was described in the past, it is fairly uncommon comparing to approaches which completely preserve skeletal integrity of chest wall. Only the later will be discussed.

Minimally invasive CABG surgery is presented trough these forms:

- Minimally invasive direct coronary artery bypass (MIDCAB)

- Endoscopic atraumatic coronary artery bypass (EndoACAB)

- Robot-assisted direct coronary artery bypass (RADCAB)

- Total endoscopic coronary artery bypass (TECAB)

- Hybrid coronary revascularisation (HCR)

Although the majority of cases are left anterior descending with left internal mammary artery (LAD-LIMA) surgery, more and more multi-vessel disease treatment are presented. 


\section{"Off Pump" Coronary Surgery}

Although it was developed using TMS, CABG surgery without using extracorporeal circulation (ECC) plays a big role in minimally invasive surgery. By avoiding ECC, patient is relieved from its harmful consequences, with outcome comparable to traditional CABG surgery in experiences centres. ${ }^{1,2}$ While majority of minimally invasive procedures still utilise ECC, there are those who do not, especially single-vessel disease treated with LAD-LIMA. As surgeons are getting familiar with coronary stabilisers and beating heart fixation, they are making a step towards safer transition to smaller incisions and comfort sacrifices. Therefore, "off pump" surgery is utterly important in development of minimally invasive CABG procedures.

\section{Patient Selection}

Same as always when novel technologies are introduced, careful patient selection and preoperative preparation are the key to success. All these minimally invasive CABG procedures provide worse exposition comparing to traditional CABG. Therefore, thorough coronarography analysis it is mandatory to access anastomosis site, the graft length needed, is coronary artery epicardially or intramyocardially placed, what is its calibre, lesion extension, etc. It could be quite difficult to determine how deep in the heart wall the coronary artery is placed, but some discrete signs could be of help: the more superficial, epicardial arteries are more mobile during contractions and more tortuous; while the more deep ones, intramyocardial (especially LAD) are straight and seem as they "dive in" and "dive out" on their way to the apex of the heart. Later cases can be technically much more demanding in minimally invasive surgery as it does not always allow visualisation of the entire LAD. Exploration of the anterior heart wall in these approaches is completely different experience to standard TMS CABG, so LAD and its branches must be carefully analysed on coronarography prior to surgery, to avoid bypassing the wrong vessel.

The restricted space adds another level of complexity to minimally invasive CABG procedures. The bigger the intrathoracic space is, endoscopic and robotic instrument manoeuvring is easier. Excess of subcutaneous fat tissue can limit the manoeuvring ability, too. Therefore, it is clear that morbidly obese and small patients are a group with significant limitations for using these technologies.

\section{Indications and Contraindica- tions}

The critics of minimally invasive CABG procedures are making a question of safety being asked first. Opposing to TMS, approaching aorta and right atrial appendage for ECC cannulation is not possible. Utilising femoral vessels could lead to risk of embolic events due to retrograde perfusion. Making anastomosis using endoscopic and robotic instruments is by far more demanding than with the open approach. MiniCABG procedures take more time, therefore pro et contra balancing of faster recovery and aesthetics (Figure 1) versus risks of demanding technique is essential. Coronary patients are usually present with the following comorbidities: left ventricular dysfunction, peripheral arterial and venous disease, chronic obstructive pulmonary disease (COPD), renal insufficiency, etc. All of this could lead to negative outcome even with traditional TMS CABG procedures, so it is clear that a special attention is needed when planning a miniCABG.

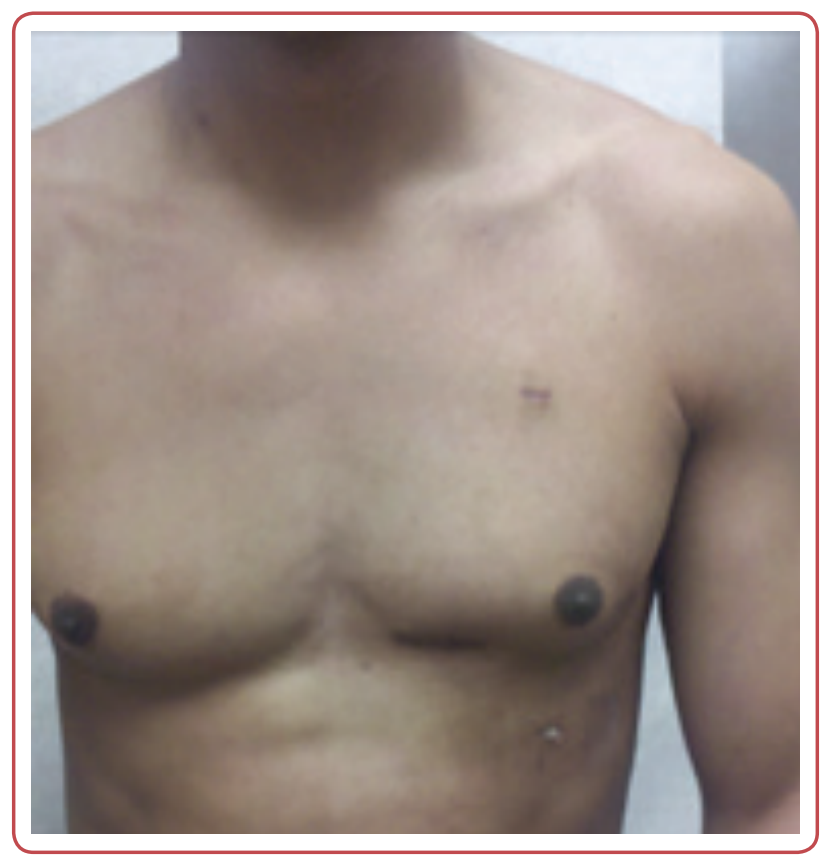

Figure 1: Aesthetic advantage of minimally invasive CABG. Two incisions for ports and left anterolateral thoracotomy of less than $5 \mathrm{~cm}$ 
In conclusion, patients undergoing miniCABG surgery could be divided into two subgroups: relatively healthy patients who wish to avoid TMS, but aim for long term result of surgical revascularisation; and elderly patients and those with severe comorbidities to whom TMS caries too much of a risk, but are not treatable with catheterisation methods and medications only. Indications for standard and miniCABG are the same, but there are several contraindications for performing miniCABG:

- Absolute - clinical: haemodynamic instability, ischaemic arrhythmias, acute coronary event, urgent conditions, cardiogenic shock;

- Relative - angiographic: intramyocardial position of coronary vessel, small diameter of coronary vessel, severely calcified coronary vessel, occluded coronary vessel without sufficient collateral filling;

- Relative - comorbidities: morbid obesity, severe respiratory insufficiency, severe peripheral vascular disease (for femoral ECC cannulation), severe left ventricular dysfunction (LVEF $<30 \%$ ), severe dilatation of left ventricle, previous TMS, previous surgery in left hemithorax, chest wall deformities, previous radiotherapy of left hemithorax, pulmonary hypertension.

\section{Minimally Invasive Direct Coro- nary Artery Bypass (MIDCAB)}

MIDCAB was first introduced in the early nineties, and gained its popularity as alternative solution to single-vessel revascularisation LAD-LIMA via TMS. ${ }^{3,4}$ It is performed trough left anterolateral thoracotomy in the fifth intercostal space with 5 to $8 \mathrm{~cm}$ skin incision and decompression of left lung using double-lumen endotracheal tube or bronchial blocker. All of the miniCABG procedures are performed by selective ventilation of the right lung or bilateral ventilation with small volume. Special retraction devices are used to elevate the anterior chest wall and to harvest LIMA graft by direct vision. When the graft is prepared and pericardiotomy performed, procedure could be carried on ether with or without utilising ECC ("off pump"). If the decision is made to put a patient on ECC, peripheral cannulation must be per- formed because cannulation of ascending aorta is practically impossible. On the other hand, if "off pump" is the option of choice, some kind of stabilisers must be used to make an anastomosis on the beating heart. Anastomosing is done in standard manner, technically identical to TMS approach.

There are several centres that published excellent results of this procedure. ${ }^{5-14}$ Although the mostly chosen option for the treatment of single-vessel LAD disease is percutaneous coronary intervention (PCI), even more so after introducing of drug eluting stents (DES), MIDCAB still holds advantage for that case in majority of analysed parameters. ${ }^{15,16}$

There are also published cases of MIDCAB treatment of multi-vessel coronary disease, with and without ECC use. ${ }^{17}$ Even though results were great, multi-vessel MIDCAB did not make it to everyday use in many centres. The reason is probably technical demands and great risk of complications because of that. Besides, postoperative pain levels must be taken in consideration (thoracotomy syndrome). ${ }^{17,} 18$ Also, a question of possibility of complete LIMA harvesting with this technique is being asked, because reaching the apex of hemithorax is impossible through fifth intercostal space incision. This could lead to coronary steal syndrome by a patent LIMA side branch.

\section{Endoscopic Atraumatic Coro- nary Artery Bypass (EndoACAB)}

This procedure introduced endoscopic techniques to CABG surgery. The patient is positioned in right lateral decubitus to expose left hemithorax, and 10 to $12 \mathrm{~mm}$ camera is inserted through the fourth of fifth intercostal space (at the mid-level of chest bone), two fingers width laterally of medio-clavicular line or by anterior axillary line. After flooding the pleural cavity with 10 to $15 \mathrm{mmHg}$ of $\mathrm{CO}_{2}$, two $5 \mathrm{~mm}$ ports are inserted parallel to camera, two intercostal spaces above and below it. The most common configuration is 2-4-6 and 3-5-7 (intercostal spaces). Harvesting of LIMA graft is performed with endoscopic instruments (Figure 2). After pericardiotomy and systemic heparinisation, a long spinal needle 
is pierced outward the chest wall, to guide the skin incision site. Then, $\mathrm{CO}_{2}$ is released from the wound so the heart and lung could return to position, and 3 to $4 \mathrm{~cm}$ incision anterolateral thoracotomy is made, followed by extraction of endoscopy ports. LIMA graft is introduced to operation field and anastomosed to LAD (usually with the "off pump" method) (Figure 3).

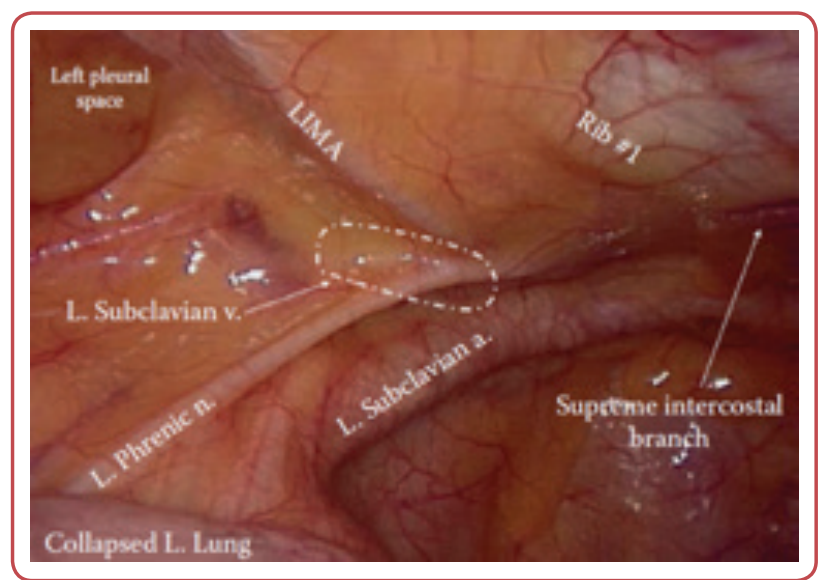

Figure 2: Left hemithorax after lung deflation, exposing LIMA and surrounding structures

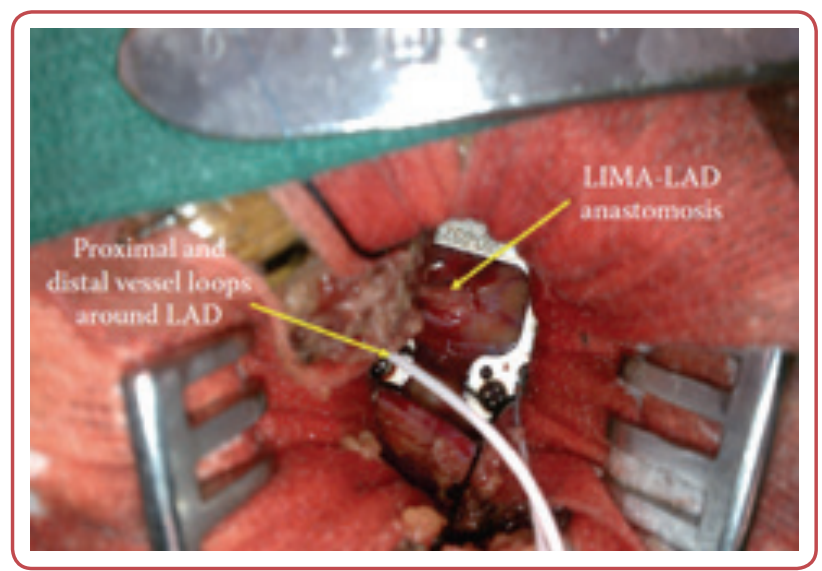

Figure 3: Making LAD-LIMA anastomosis through $3 \mathrm{~cm}$ incision anterolateral thoracotomy

EndoACAB made good results as a single procedure (LAD-LIMA), and as a part of the hybrid coronary revascularisation (HCR), too. ${ }^{19-22} \mathrm{~A}$ long learning curve is also expected with this miniCABG procedure, because endoscopic LIMA harvesting is technically quite demanding, just as making an anastomosis with 3 to $4 \mathrm{~cm}$ skin incision thoracotomy.

\section{Robot-Assisted Direct Coro- nary Artery Bypass (RADCAB)}

RADCAB (Figure 4) represents the next step in the evolution of miniCABG surgery techniques. This procedure combines technological advances of robotised telemanipulation with direct anastomosing. Da Vinci system (Figure 5) provides a combination of high-definition image visualisation with 3D-flexible instruments, which enables complex manipulations in the operative field. RADCAB largely resembles EndoACAB procedure. After LIMA is harvested with the Da Vinci system, pericardiotomy is performed. Thoracotomy location is determined by spinal needle under endoscopic guidance, after which the anastomosis is made with standard instruments and stabilators.

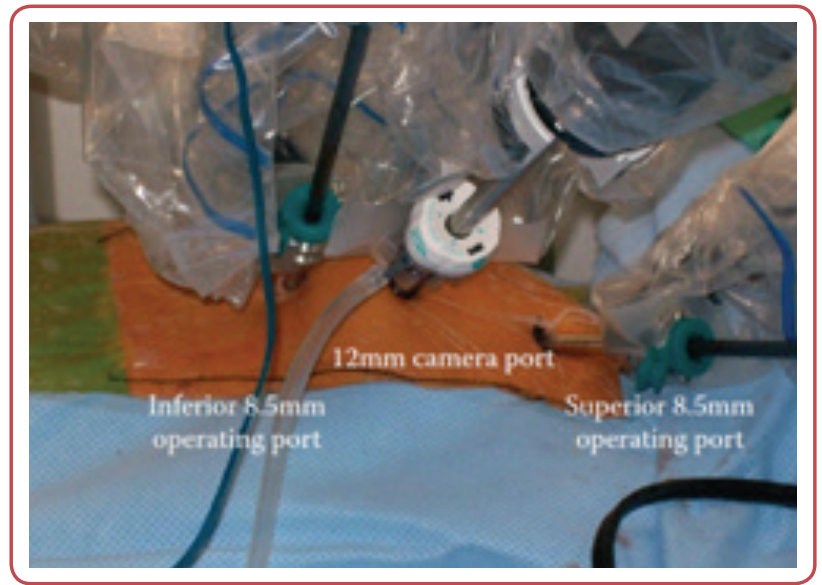

Figure 4: Ports position in RADCAB procedure

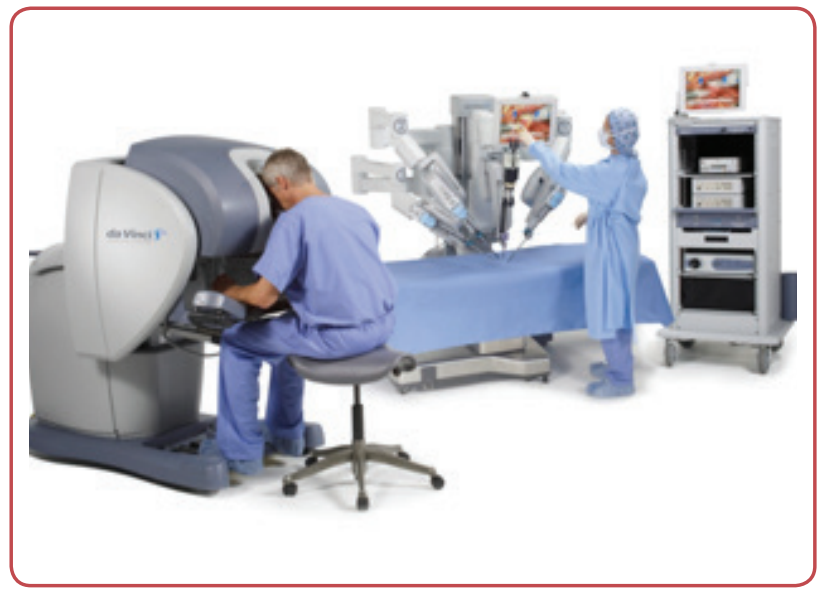

Figure 5: The Da Vinci surgical system 
Although significant prospective studies that compare RADCAB with conventional CABG surgery have not yet been performed, a few minor studies showed safety and feasibility of this method..$^{8,23-25}$ RADCAB provides greater flexibility and visibility in comparison to endoscopic methods, however, the lack of tactile feedback with manipulation represents one important disadvantage. Few centres used this method as a step in the transition towards TECAB.

\section{Totally Endoscopic Coronary Artery Bypass (TECAB)}

TECAB represents the least invasive, but also technically the most complex procedure for heart revascularisation through closed chest. This procedure is performed in only a couple of highly specialised centres across the world, and can be performed with ECC, as well as "off pump". ECC cannulation is performed through femoral or axillar blood vessels. LIMA/RIMA is harvested with robot-assistance and pericardiotomy is performed before ECC initiation. Heart is excluded from circulation with the use of endo-aortic occluder (introduced directly through axillar or femoral approach) and then cardioplegic solution is administered anterogradely. Anastomosing is performed with robot-assistance. Da Vinci system of the latest generation has a fourth arm that can be used for stabilators application (in "off pump" TECAB). It must be mentioned that "off pump" TECAB technique is reserved only for revascularisation of LAD and its diagonal branches. For inferior and lateral wall interventions, ECC initiation and lung deflation are necessary, by which haemodynamic instability caused by heart manipulation is avoided.

There still have not been any prospective or observational studies to compare TECAB with traditional CABG surgery through medial sternotomy, nor with other minimally invasive CABG techniques. Nevertheless, early results of the few centres performing TECAB are encouraging. These are mainly LAD-LIMA interventions, although there are also cases of multivessel coronary artery disease management with this method. ${ }^{26-31}$

TECAB is considered the technically most chal- lenging minimally invasive cardiac surgical intervention. In contrast to robot-assisted mitral surgery which uses larger dimension suture material and is sutured through the thick mitral annulus, suturing of coronary anastomoses is extremely delicate process. Therefore, learning curve is present. There is no room for flaws, considering the high risk of complications. The learning curve is notable when the extended timing of the interventions is taken into consideration..$^{32}$ The most experienced centres report a duration of LAD-LIMA TECAB procedure of 295 minutes ( $4.9 \mathrm{~h}$ ) in average, while TECAB in ECC with bilateral IMA revascularisation requires 502 minutes $(8.4 \mathrm{~h})$ in average. ${ }^{33}$ Obviously, this raised a question of the long-term efficiency of TECAB procedure versus standard CABG surgery. ${ }^{34}$

The price of Da Vinci system and the consumable supplies for its use in minimally invasive procedures need to be considered, as well as the extended duration of the operations. All of these represent a certain limit in comparison to standard CABG surgery. In order for wider acceptance of RADCAB and TECAB technologies and techniques, the balance between procedure costs on one side, and the reduction of hospital stay and expected complications on the other side, needs to be established. ${ }^{13}$

\section{Hybrid Coronary Revasculari- sation ( $\mathrm{HCR})$}

HCR represents a treatment strategy which involves the experience of both cardiac surgeons and invasive cardiologists. This method mostly includes minimally invasive LAD-LIMA revascularisation in combination with PCI with DES on non-LAD coronary arteries. This type of multivessel coronary artery disease management drew the attention of both cardiac surgery and cardiology communities, since they agree that LIMA represents the most effective and long-lasting solution for LAD management. On the other hand, LIMA-LAD anastomosis is probably most credible for CABG longevity. ${ }^{35}$ The reported incidence of venous (saphenous) grafts failure and the lower degree of DES restenosis raised a question: "Which is the optimal method for management of lesions on non-LAD blood vessels (venous graft or DES)?"36-38 
HCR offers the advantages of both options: longevity of LAD-LIMA graft with minimally invasive surgery and percutaneous treatment with the use of DES for non-LAD blood vessels. Furthermore, this approach confines the disadvantages of the both methods: the invasiveness of the traditional CABG surgery and the use of unstable venous grafts on one hand, as well as short-lasting management of proximal LAD lesions with PCI on the other hand are avoided.

In terms of the interventions timing, HCR can be performed in three ways: PCI first; surgery first, and simultaneously in hybrid operating room (Figure 6). If the surgery is initially performed, operating under double antiplatelet therapy due to stents is avoided. PCI is primarily performed in patients with acute coronary syndrome when the culprit lesion is not on LAD. The existence of the hybrid operating room is the ideal scenario, because it provides the highest comfort for patient, shorter hospital time, and avoids ischaemic complications in the period between two HCR stages. Moreover, the patency of LIMA-LAD graft can be confirmed with graftography in the hybrid operating room, so a potentially inadequate anastomosis can be corrected. These benefits come with a price for coordinating double teams, as well as risk of perioperative bleeding related to the loading dose of antiplatelet therapy.

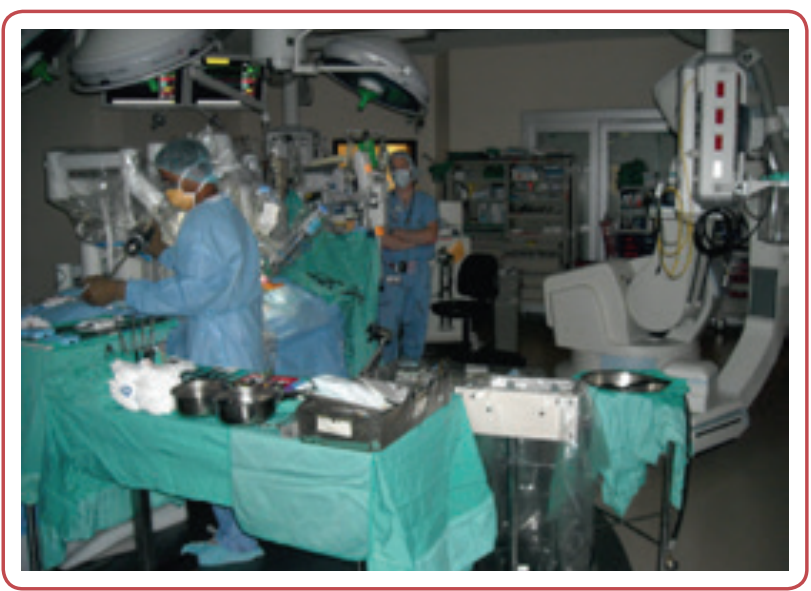

Figure 5: Hybrid operating teatre

Careful patient selection is necessary for optimal results. An ideal candidate is the one with proximal LAD lesion and focal lesions on ACD and/ or $\mathrm{Cx}$, which would be treated percutaneously anyway, if there was no LAD lesion present. More complex lesions, such as calcified coronary arteries, bifurcational lesions, chronically occluded lesions on non-LAD arteries, joined with proximal LAD lesions, are best treated with traditional
CABG surgery. The ideal population for undergoing HCR from anatomic and clinical point of view has not been defined. This method can be used for treatment of distal "left main" stenoses, as well as distal "left main" stenoses that propagate into the bifurcation, by making LAD-LIMA anastomosis, after which DES is implanted into "left main" towards Cx. Proximal and medial "left main" lesions are not suitable for HCR due to competitive flow development of MMR cannot be a final decision without a strong backup of long-term epidemiological data.

\section{Conclusion}

Minimally invasive CABG techniques continue their evolution to the present day. Unfortunately, these are still limited only to the specialised centres across the world and have not been accepted by the majority of cardiac surgeons. MIDCAB is the most common procedure, while RADCAB and TECAB are the least common, however, their use tends to get higher. Although robot-surgery enables excellent visualisation and exposition in small spaces, implementing these new techniques requires not only significant financial resources, but also dedication of a whole team in adopting new skills.

A surgeon who is starting to practice miniCABG surgery needs to be ready for long duration of the interventions, higher rate of conversions to sternotomy, and significant learning curve. Conversion should not be considered as a failure under any condition, as the quality of anastomosis must never be compromised by avoiding it!

In order for surgical community to adopt these technologies, it is necessary to achieve a few goals: quality and longevity of the solutions must be confirmed by more centres; operation timing needs to be reduced to the level that is comparable to standard CABG methods; the higher financial cost needs to be balanced with lower postoperative expenses, including shorter stay in the intensive care unit, shorter duration of the postoperative mechanical ventilation, faster recovery and shorter hospital stay; close cooperation with cardiologists, who will accept and refer patients to these treatment methods, must be established. Great results that have been published on the subject of minimally invasive revascularisation methods support the potential of these alternative approaches to evolve in the near future. 


\section{Acknowledgements}

None.

\section{References}

1. Puskas JD, Kilgo PD, Lattouf OM, Thourani VH, Cooper WA, Vassiliades TA, et al. Off-pump coronary bypass provides reduced mortality and morbidity and equivalent 10-year survival. Ann Thorac Surg 2008 Oct;86(4):1139-46.

2. Angelini GD, Culliford L, Smith DK, Hamilton MC, Murphy GJ, Ascione R, et al. Effects of on- and off-pump coronary artery surgery on graft patency, survival, and health-related quality of life: long-term follow-up of 2 randomized controlled trials. J Thorac Cardiovasc Surg 2009 Feb;137(2):295-303.

3. Calafiore AM, Giammarco GD, Teodori G, Bosco G, D'Annunzio E, Barsotti A, et al. Left anterior descending coronary artery grafting via left anterior small thoracotomy without cardiopulmonary bypass. Ann Thorac Surg 1996 Jun;61(6):1658-65.

4. Subramanian VA, McCabe JC, Geller CM. Minimally invasive direct coronary artery bypass grafting: two-year clinical experience. Ann Thorac Surg Dec 1997;64(6):1648-55.

5. Mack MJ, Magovern JA, Acuff TA, Landreneau RJ, Tennison DM, Tinnerman EJ, et al. Results of graft patency by immediate angiography in minimally invasive coronary artery surgery. Ann Thorac Surg 1999 Aug;68(2):383-90.

6. Holzhey DM, Jacobs S, Mochalski M, Walther T, Thiele H, Mohr FW, et al. Seven-year follow-up after minimally invasive direct coronary artery bypass: experience with more than 1300 patients. Ann Thorac Surg 2007 Jan;83(1):108-14.

7. Thiele H, Neumann-Schniedewind P, Jacobs S, Boudriot E, Walther T, Mohr FW, et al. Randomized comparison of minimally invasive direct coronary artery bypass surgery versus sirolimus-eluting stenting in isolated proximal left anterior descending coronary artery stenosis. J Am Coll Cardiol 2009 Jun 23;53(25):2324-31.

8. Kiaii B, McClure RS, Stitt L, Rayman R, Dobkowski WB, Jablonsky G, et al. Prospective angiographic comparison of direct, endoscopic, and telesurgical approaches to harvesting the internal thoracic artery. Ann Thorac Surg 2006 Aug;82(2):624-8.

9. Fraund S, Herrmann G, Witzke A, Hedderich J, Lutter G, Brandt M, et al. Midterm follow-up after minimally invasive direct coronary artery bypass grafting versus percutaneous coronary intervention techniques. Ann Thorac Surg 2005 Apr;79(4):1225-31.

10. Mehran R, Dangas G, Stamou SC, Pfister AJ, Dullum MK, Leon MB, et al. One-year clinical outcome after minimally invasive direct coronary artery bypass. Circulation 2000 Dec 5;102(23):2799-802.

11. Zimarino M, Gallina S, Di Fulvio M, Di Mauro M, Di Giammarco G, De Caterina R, et al. Intraoperative ischemia and long-term events after minimally invasive coronary surgery. Ann Thorac Surg 2004 Jul;78(1):135-41.

\section{Conflict of interest}

None.

12. Jaffery Z, Kowalski M, Weaver WD, Khanal S. A meta-analysis of randomized control trials comparing minimally invasive direct coronary bypass grafting versus percutaneous coronary intervention for stenosis of the proximal left anterior descending artery. Eur J Cardiothorac Surg Apr 2007;31(4):691-7.

13. Poston RS, Tran R, Collins M, Reynolds M, Connerney I, Reicher B, et al. Comparison of economic and patient outcomes with minimally invasive versus traditional offpump coronary artery bypass grafting techniques. Ann Surg 2008 Oct;248(4):638-46.

14. Al-Ruzzeh S, Mazrani W, Wray J, Modine T, Nakamura K, George S, et al. The clinical outcome and quality of life following minimally invasive direct coronary artery bypass surgery. J Card Surg 2004 Jan-Feb;19(1):12-6.

15. Loop FD, Lytle BW, Cosgrove DM, Stewart RW, Goormastic M, Williams GW, et al. Influence of the internal-mammary-artery graft on 10-year survival and other cardiac events. N Engl J Med 1986 Jan 2;314(1):1-6.

16. Drenth DJ, Winter JB, Veeger NJ, Monnink SH, van Boven AJ, Grandjean JG, et al. Minimally invasive coronary artery bypass grafting versus percutaneous transluminal coronary angioplasty with stenting in isolated high-grade stenosis of the proximal left anterior descending coronary artery: six months' angiographic and clinical follow-up of a prospective randomized study. J Thorac Cardiovasc Surg 2002 Jul;124(1):130-5.

17. Lichtenberg A, Hagl C, Harringer W, Klima U, Haverich A. Effects of minimal invasive coronary artery bypass on pulmonary function and postoperative pain. Ann Thorac Surg Aug 2000;70(2):461-5.

18. Ng PC, Chua AN, Swanson MS, Koutlas TC, Chitwood WR Jr, Elbeery JR. Anterior thoracotomy wound complications in minimally invasive direct coronary artery bypass. Ann Thorac Surg 2000 May;69(5):1338-41.

19. Vassiliades T Jr. Enabling technology for minimally invasive coronary artery bypass grafting. Semin Thorac Cardiovasc Surg Fall 2009;21(3):237-44.

20. Vassiliades TA Jr, Douglas JS, Morris DC, Block PC, Ghazzal $\mathrm{Z}$, Rab ST, et al. Integrated coronary revascularization with drug-eluting stents: immediate and seven-month outcome. J Thorac Cardiovasc Surg 2006 May;131(5):956-62.

21. Vassiliades TA, Kilgo PD, Douglas JS, Babaliaros VC, Block PC, Samady H, et al. Clinical outcomes after hybrid coronary revascularization versus off-pump coronary artery bypass: a prospective evaluation. Innovations (Phila) 2009 Nov;4(6):299-306.

22. Vassiliades TA Jr., Reddy VS, Puskas JD, Guyton RA. Longterm results of the endoscopic atraumatic coronary artery bypass. Ann Thorac Surg Mar 2007;83(3):979-85.

23. Oehlinger A, Bonaros N, Schachner T, Ruetzler E, Friedrich G, Laufer G, et al. Robotic endoscopic left internal mammary artery harvesting: what have we learned after 100 cases? Ann Thorac Surg 2007 Mar;83(3):1030-4. 
24. Srivastava S, Gadasalli S, Agusala M, Kolluru R, Naidu J, Shroff M, et al. Use of bilateral internal thoracic arteries in CABG through lateral thoracotomy with robotic assistance in 150 patients. Ann Thorac Surg 2006 Mar;81(3):800-6.

25. Subramanian VA, Patel NU, Patel NC, Loulmet DF. Robotic assisted multivessel minimally invasive direct coronary artery bypass with port-access stabilization and cardiac positioning: Paving the way for outpatient coronary surgery? Ann Thorac Surg May 2005;79(5):15906.

26. Argenziano M, Katz M, Bonatti J, Srivastava S, Murphy D, Poirier R, et al; TECAB Trial Investigators. Results of the prospective multicenter trial of robotically assisted totally endoscopic coronary artery bypass grafting. Ann Thorac Surg 2006 May;81(5):1666-75.

27. de Cannière $D$, Wimmer-Greinecker $G$, Cichon R, Gulielmos V, Van Praet F, Seshadri-Kreaden U, et al. Feasibility, safety, and efficacy of totally endoscopic coronary artery bypass grafting: multicenter European experience. J Thorac Cardiovasc Surg 2007 Sep;134(3):710-6.

28. Bonatti J, Schachner T, Bonaros N, Oehlinger A, Wiedemann D, Ruetzler E, et al. Effectiveness and safety of total endoscopic left internal mammary artery bypass graft to the left anterior descending artery. Am J Cardiol 2009 Dec 15;104(12):1684-8.

29. Bonatti J, Schachner T, Bonaros N, Lehr EJ, Zimrin D, Griffith B. Robotically assisted totally endoscopic coronary bypass surgery. Circulation 2011 Jul 12;124(2):236-44.

30. Srivastava S, Gadasalli S, Agusala M, Kolluru R, Barrera $\mathrm{R}$, Quismundo S, et al. Robotically assisted beating heart totally endoscopic coronary artery bypass (TECAB). Is there a future? Innovations (Phila) 2008 Mar;3(2):52-8.

31. Srivastava S, Gadasalli S, Agusala M, Kolluru R, Barrera R, Quismundo S, et al. Beating heart totally endoscopic coronary artery bypass. Ann Thorac Surg 2010 Jun;89(6):1873--80.
32. Bonatti J, Schachner T, Bonaros N, Ohlinger A, Danzmayr M, Jonetzko P, et al. Technical challenges in totally endoscopic robotic coronary artery bypass grafting. J Thorac Cardiovasc Surg 2006 Jan;131(1):146-53.

33. Wiedemann D, Bonaros N, Schachner T, Weidinger F, Lehr EJ, Vesely M, et al. Surgical problems and complex procedures: issues for operative time in robotic totally endoscopic coronary artery bypass grafting. J Thorac Cardiovasc Surg 2012 Mar;143(3):639-47.

34. Kappert U, Tugtekin SM, Cichon R, Braun M, Matschke K. Robotic totally endoscopic coronary artery bypass: a word of caution implicated by a five-year follow-up. J Thorac Cardiovasc Surg 2008 Apr;135(4):857-62.

35. Hannan EL, Wu C, Walford G, Culliford AT, Gold JP, Smith $\mathrm{CR}$, et al. Drug-eluting stents vs. coronary-artery bypass grafting in multivessel coronary disease. $\mathrm{N}$ Engl J Med 2008 Jan 24;358(4):331-41.

36. Alexander $\mathrm{JH}$, Hafley G, Harrington RA, Peterson ED, Ferguson TB Jr, Lorenz TJ, et al; PREVENT IV Investigators. Efficacy and safety of edifoligide, an E2F transcription factor decoy, for prevention of vein graft failure following coronary artery bypass graft surgery: PREVENT IV: a randomized controlled trial. JAMA 2005 Nov 16;294(19):2446-54.

37. de Cannière $\mathrm{D}$, Jansens JL, Goldschmidt-Clermont $\mathrm{P}$, Barvais L, Decroly P, Stoupel E. Combination of minimally invasive coronary bypass and percutaneous transluminal coronary angioplasty in the treatment of double-vessel coronary disease: Two-year follow-up of a new hybrid procedure compared with "on-pump" double bypass grafting. Am Heart J 2001 Oct;142(4):563-70.

38. Byrne JG, Leacche M, Vaughan DE, Zhao DX. Hybrid cardiovascular procedures. JACC Cardiovasc Interv 2008 Oct;1(5):459-68. 